\title{
THE INFLUENCE OF GRAPHITE INOCULANTS AND WALL THICKNESS OF THE CASTINGS FROM NODULAR GRAPHITE CAST IRON ON THE STRUCTURE AND MECHANICAL PROPERTIES
}

\author{
Jaromír ROUČKA, Václav KAŇA, Vítězslav PERNICA, Dominika NYÉKYOVÁ, Antonín ZÁDĚRA \\ Brno University of Technology, Faculty of Mechanical Engineering, Brno, Czech Republic, EU, \\ roucka@fme.vutbr.cz
}

https://doi.org/10.37904/metal.2021.4074

\begin{abstract}
The research examined the influence of different kinds of graphite inoculants when casting nodular cast iron on the structure and mechanical properties of the castings. The test alloy was a nodular cast iron corresponding with the ČSN EN GJS 450 standard. The modification was done with a VM 63M alloy by a Sandwich method. A comparison was made of the inoculating effects of 3 sorts of inoculants applied by a single-stage modification. Test moulds samples of Y1-Y4 type complying with the ČSN EN 1563 standard were cast. These samples were tested for their mechanical properties using the tensile, hardness and impact tests. A metallographic evaluation of the graphite and basic metal structure was made for all the samples.
\end{abstract}

Keywords: Ductile iron, inoculation, wall thickness, structure, mechanical properties

\section{INTRODUCTION}

The utility properties of the nodular cast iron depend on the structure of the iron, morphology and dispersion of the structural components. The precipitation of the graphite parts, their shape, size and even distribution of the nodules are significant [1-3]. The solidification rate and presence of some trace elements can considerably influence the precipitation of the graphite, decrease nodularity and give rise to its anomalies. The morphology of the graphite parts influences the diffusion distances between the elements during solidification and austenite transformation thus having a significant influence on the structure of the metal matrix. Due to the antigraphitic effect of the modifying magnesium, the conditions for the graphite precipitation are less favourable than when the lamellar graphite is being formed, and the cast iron has, especially in castings with small wall thickness, higher susceptibility to the formation of metastable structures. Therefore, when making castings from nodular iron, effective graphite inoculation is essential [4].

What is mostly used in practice for graphite inoculation are inoculants on the basis of Fe-Si alloy with the content of some minority elements which influence the graphite nucleation, shape stability of the nodules, duration of the inoculation effect, facilitate the process of dissolving inoculants and have other effects too [5]. Therefore, these experiments were carried out with three different types of inoculants for making the sample castings from the nodular iron. The purpose of these experiments was to assess their influence on the structure and mechanical properties of castings with different wall thicknesses.

\section{EXPERIMENTAL TESTS}

\subsection{Moulds}

The influence on the structure and mechanical properties was tested on the $\mathrm{Y} 1, \mathrm{Y} 2, \mathrm{Y} 3$ and $\mathrm{Y} 4$ specimens according to the ČSN EN 1563 standard. The thicknesses of the casted blocks from which the specimens were made are $\mathrm{Y} 1-12.5 \mathrm{~mm}, \mathrm{Y} 2-25 \mathrm{~mm}, \mathrm{Y} 3-50 \mathrm{~mm}$ and $\mathrm{Y} 4-75 \mathrm{~mm}$. 
The sample moulds were made from self-hardening mixtures on the basis of silica sand with Geopol binder. All castings in the moulds were poured through a common sprue.

\subsection{Metallurgy}

The metal was melted in an induction furnace with a crucible capacity of $120 \mathrm{~kg}$. The goal was to melt down cast iron by the ČSN EN 450 class with a some proportion of perlite to make it possible to monitor besides graphite the changes of perlite content in each specimen as well.

Required chemical composition: 3.5-3.7 \% C, 2.3-2.5 \% Si, 0.3 \% Mn, CE - 4.3-4.4.

Charge: steel - rolled bars, cast iron scrap, pig iron, FeSi45, carbonizer

Modification: Sandwich one-step modification

Modifier VM 63M, dosage $0.8 \%$ - stated composition: $6-6.5 \% \mathrm{Mg}, 1.9 \% \mathrm{Ca}, 0.7 \% \mathrm{KVZ}, 45 \% \mathrm{Si}$

Modification temperature $1,520-1,540{ }^{\circ} \mathrm{C}$, pouring temperature: $1,380-1,415^{\circ} \mathrm{C}$

Time delay between modification and pouring 2-3 $\mathrm{min}$

Inoculation: One-step inoculation - dosage $0.45 \%$

Inoculants - foundry alloy $\mathrm{Fe}-\mathrm{Si}$ with content of $\mathrm{Ba}, \mathrm{Al}$ and $\mathrm{Bi}$ elements, in-house designation of the inoculants: In-Ba, In-Al and In-Bi, grain size 1-4 mm, composition see Table 1

Table 1 Chemical composition of inoculants stated by manufacturers

\begin{tabular}{|c|c|c|c|c|c|c|c|}
\hline Inoculant & $\mathbf{S i}(\mathbf{w t} \%)$ & $\mathbf{A l}(\mathbf{w t} \%)$ & $\mathbf{C a}(\mathbf{w t} \%)$ & $\mathbf{B i}(\mathbf{w t} \%)$ & $\mathbf{K V Z}(\mathbf{w t} \%)$ & $\mathbf{M g}(\mathbf{w t} \%)$ & $\mathbf{B a}(\mathbf{w t} \%)$ \\
\hline $\mathrm{In}-\mathrm{Bi}$ & $62-68$ & $\max 1 \%$ & $1.8-2.4$ & $\mathbf{0 . 8 - 1 . 2}$ & $0.8-1.2$ & - & - \\
\hline $\mathrm{In}-\mathrm{Al}$ & $68-73$ & $\mathbf{3 . 2 - 4 . 5}$ & $0.3-1.5$ & - & traces & traces & - \\
\hline $\mathrm{In}-\mathrm{Ba}$ & $65-70$ & $1-1.5$ & $1-1.5$ & - & - & - & $\mathbf{2 - 2 . 5}$ \\
\hline
\end{tabular}

\subsection{Assessment of the mechanical properties and metallographic structure}

The tests of the mechanical properties were done according to the ČSN EN ISO 6892-1 standard. The specimens for the tensile test and for hardness measurement were made from cast blocks according to DIN 50125. The $\phi 6 \mathrm{~mm}$ bars were made from $Y 1$ blocks and the $\phi 10 \mathrm{~mm}$ bars from the blocks $Y 2-Y 4$. The impact work values are obtained according to the ČSN ISO 148-1 standard on V-notched bars. Hardness was measured as HBW 5/750. The values of the tensile and impact tests stated in the tables are always the average values obtained from three measurements and the hardness test values from four measurements.

Metallographic assessment was done by optical microscopy in the unetched state and etched state by $2 \%$ Nital and an image analysis was carried out by Olympus DSX510 microscope with using Olympus Stream Essential software.

\subsection{The influence of the castings wall thickness on the properties}

The tests should reveal how the thickness of the specimens and the type of inoculant affect the structure and mechanical properties. The layout of the castings in the mould is shown in Figure 1. The chemical composition of the tested cast irons is given in Table 2.

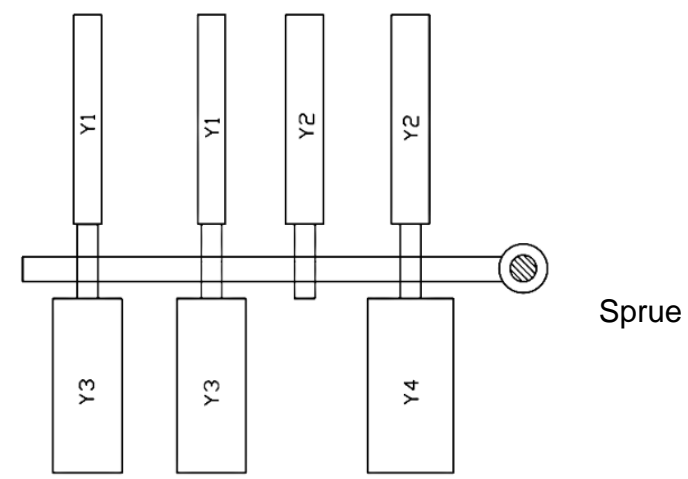

Figure 1 Layout of the mould 
Table 2 Chemical composition of the melts

\begin{tabular}{|c|c|c|c|c|c|c|c|c|c|c|c|c|}
\hline Sample & Inoculant & $\begin{array}{c}\text { Dosage } \\
(\%)\end{array}$ & $\begin{array}{c}\text { Temperature } \\
\left.\text { modification/pouring ( }{ }^{\circ} \mathbf{C}\right)\end{array}$ & $\begin{array}{c}\mathbf{C} \\
(\mathbf{w t .} \%)\end{array}$ & $\begin{array}{c}\mathbf{S i} \\
(\mathbf{w t} . \%)\end{array}$ & $\begin{array}{c}\mathbf{M n} \\
(\mathbf{w t} . \%)\end{array}$ & $\begin{array}{c}\mathbf{P} \\
(\mathbf{w t} . \%)\end{array}$ & $\begin{array}{c}\mathbf{S} \\
(\mathbf{w t} . \%)\end{array}$ & $\begin{array}{c}\mathbf{C r} \\
(\mathbf{w t} . \%)\end{array}$ & $\begin{array}{c}\mathbf{B i} \\
(\mathbf{w t} \%)\end{array}$ & $\begin{array}{c}\mathbf{M g} \\
(\mathbf{w t} \%)\end{array}$ & $\mathbf{C}$ ekv \\
\hline 515 & In-Ba & 0.45 & $1,540 / 1,380$ & 3.48 & 2.41 & 0.30 & 0.027 & 0.010 & 0.045 & $<0.007$ & 0.039 & 4.28 \\
\hline 516 & In-Al & 0.45 & $1,540 / 1,390$ & 3.68 & 2.16 & 0.31 & 0.033 & 0.012 & 0.05 & $<0.007$ & 0.050 & 4.41 \\
\hline 517 & In-Bi & 0.45 & $1,539 / 1,375$ & 3.55 & 2.28 & 0.32 & 0.030 & 0.012 & 0.05 & $<0.007$ & 0.037 & 4.32 \\
\hline
\end{tabular}

The values of the mechanical properties are stated in Table 3. The influence of the block thicknesses on the mechanical properties is shown in Figure 2.

Table 3 Mechanical properties of the $515-517$ samples

\begin{tabular}{|c|c|c|c|c|c|c|c|}
\hline Sample & Inoculant & Block & $R_{p 0,2}(\mathrm{MPa})$ & $\mathbf{R}_{\mathrm{m}}(\mathrm{MPa})$ & A (\%) & HBW & $\mathrm{KV}(\mathrm{J})$ \\
\hline \multirow{4}{*}{515} & \multirow{4}{*}{ In-Ba } & Y1 & 330 & 512 & 16.6 & 196 & 7.8 \\
\hline & & Y2 & 314 & 489 & 17.2 & 174 & 9.6 \\
\hline & & Y3 & 330 & 530 & 13.8 & 182 & 9.0 \\
\hline & & Y4 & 292 & 444 & 18.2 & 160 & 11.7 \\
\hline \multirow{4}{*}{516} & \multirow{4}{*}{$\mid \mathrm{In}-\mathrm{Al}$} & $\mathrm{Y} 1$ & 332 & 540 & 12.8 & 189 & 8.7 \\
\hline & & Y2 & 308 & 501 & 13.4 & 174 & 9.8 \\
\hline & & Y3 & 303 & 494 & 14.1 & 171 & 10.6 \\
\hline & & Y4 & 275 & 429 & 19.5 & 156 & 13.7 \\
\hline \multirow{4}{*}{517} & \multirow{4}{*}{ In-Bi } & $\mathrm{Y} 1$ & 327 & 533 & 12.6 & 202 & 7.7 \\
\hline & & Y2 & 305 & 485 & 13.1 & 177 & 9.3 \\
\hline & & Y3 & 302 & 480 & 13 & 175 & 9 \\
\hline & & Y4 & 288 & 451 & 14.9 & 163 & 10.6 \\
\hline
\end{tabular}

Table 4 Mechanical properties of Y3 blocks with different types of inoculant

\begin{tabular}{|c|c|c|c|c|c|c|}
\hline Sample & Inoculant & $\mathbf{R}_{\mathbf{p 0 , 2}}$ (MPa) & $\mathbf{R}_{\mathbf{m}}(\mathbf{M P a})$ & $\mathbf{A}(\%)$ & $\mathbf{K V}(\mathbf{J})$ & HBW \\
\hline 515 & In-Ba & 330 & 530 & 13.8 & 9.0 & 182 \\
\hline 516 & In-Al & 303 & 494 & 14.1 & 10.6 & 171 \\
\hline 517 & In-Bi & 302 & 480 & 13 & 9.0 & 175 \\
\hline
\end{tabular}

Figure 3 shows that there is no significant difference in the properties of cast block $Y 3$ inoculated with different inoculants. The respective values are given in Table 4. The cast iron inoculated with In-Al has somewhat lower strength properties $R_{m}, R_{p 0,2}$, and HBW, which corresponds to higher plastic properties given by elongation $A$ and to the impact energy represented by the $\mathrm{KV}$ value. These trends may be explained by the relevant values of the carbon equivalent $C E$ too and cannot be regarded as the exclusive influence of the inoculants.

\subsection{The influence of the castings wall thickness on the structure}

An image analysis of graphite was carried out on the block samples - Figure 4 and assessed according to the ČSN EN ISO 945-1 standard - Table 5. Dependencies of the parameters of graphite are shown in Figure 5. 

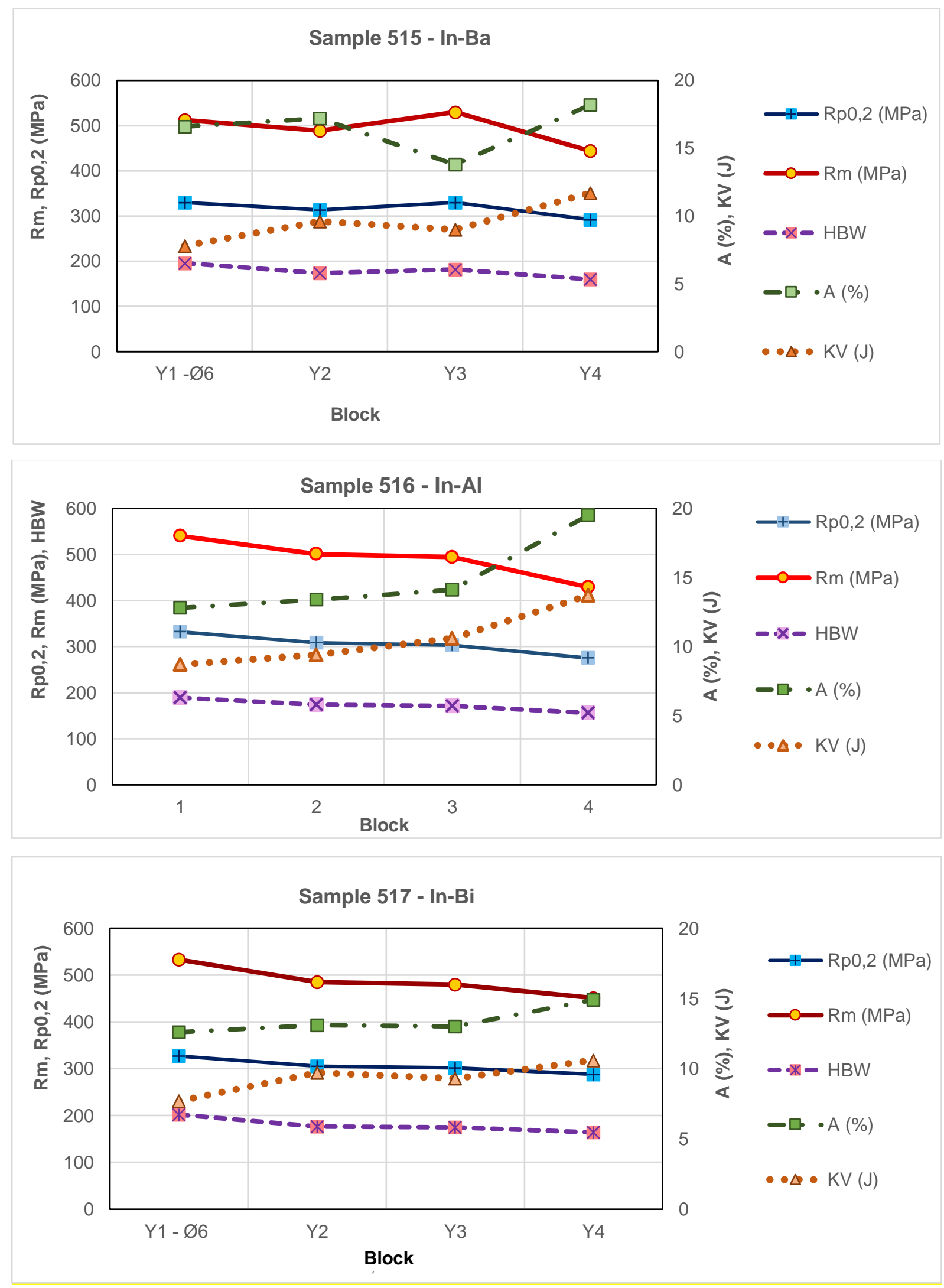

Figure 2 The influence of the wall thickness of the castings on the mechanical properties 


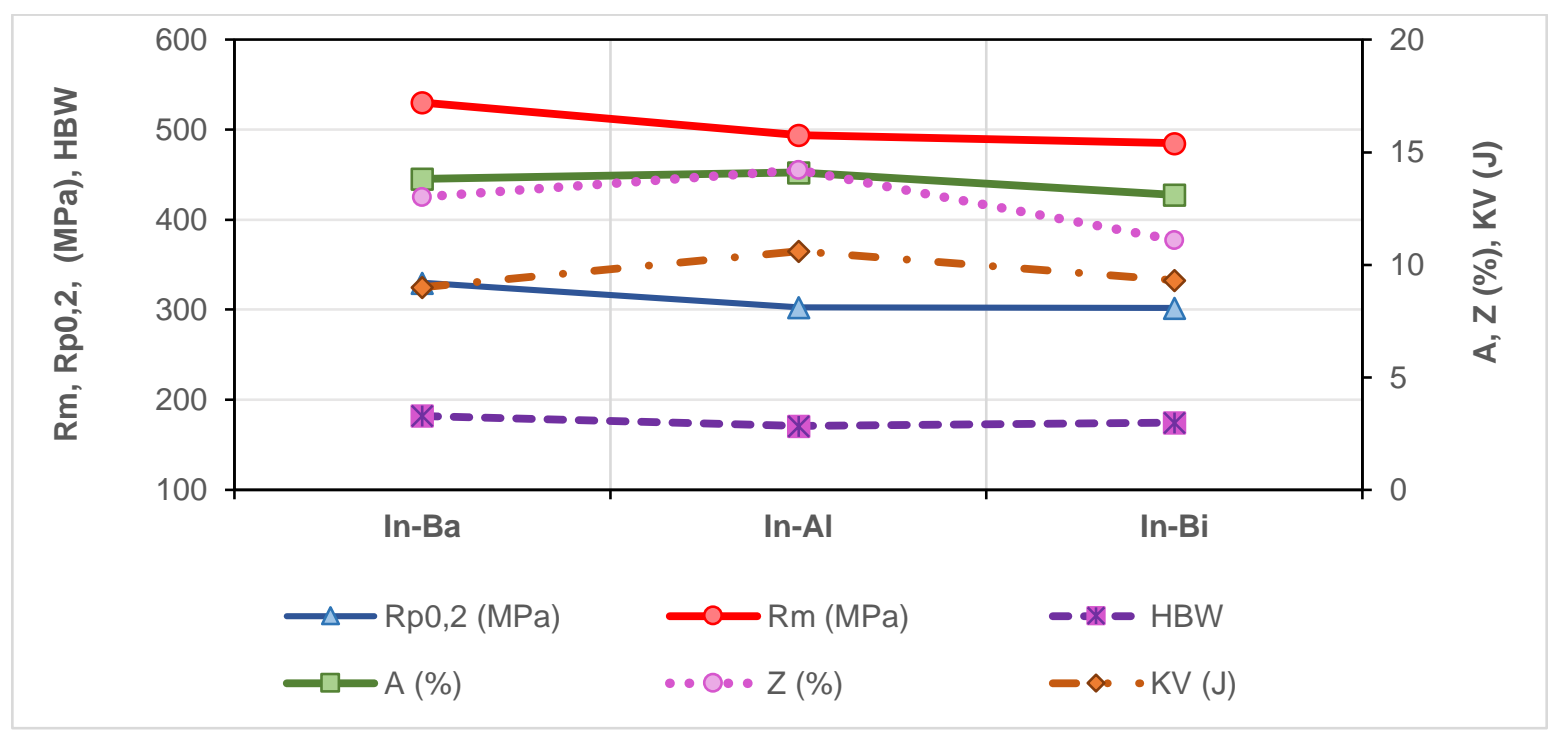

Figure 3 Comparison of the mechanical properties of the $\mathrm{Y} 3$ bodies

In-Ba Y1

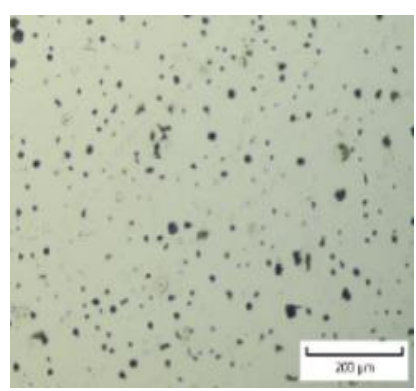

In-Al

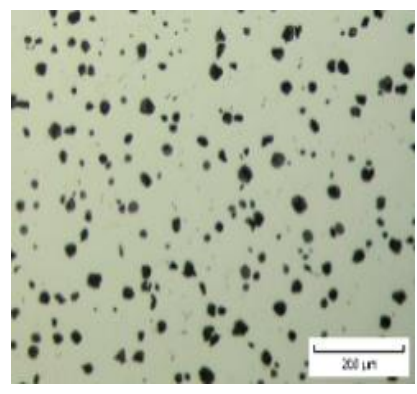

\section{In-Bi}

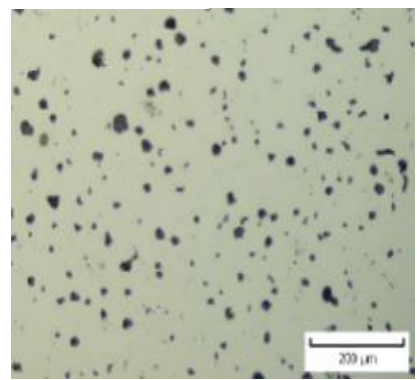

Y2
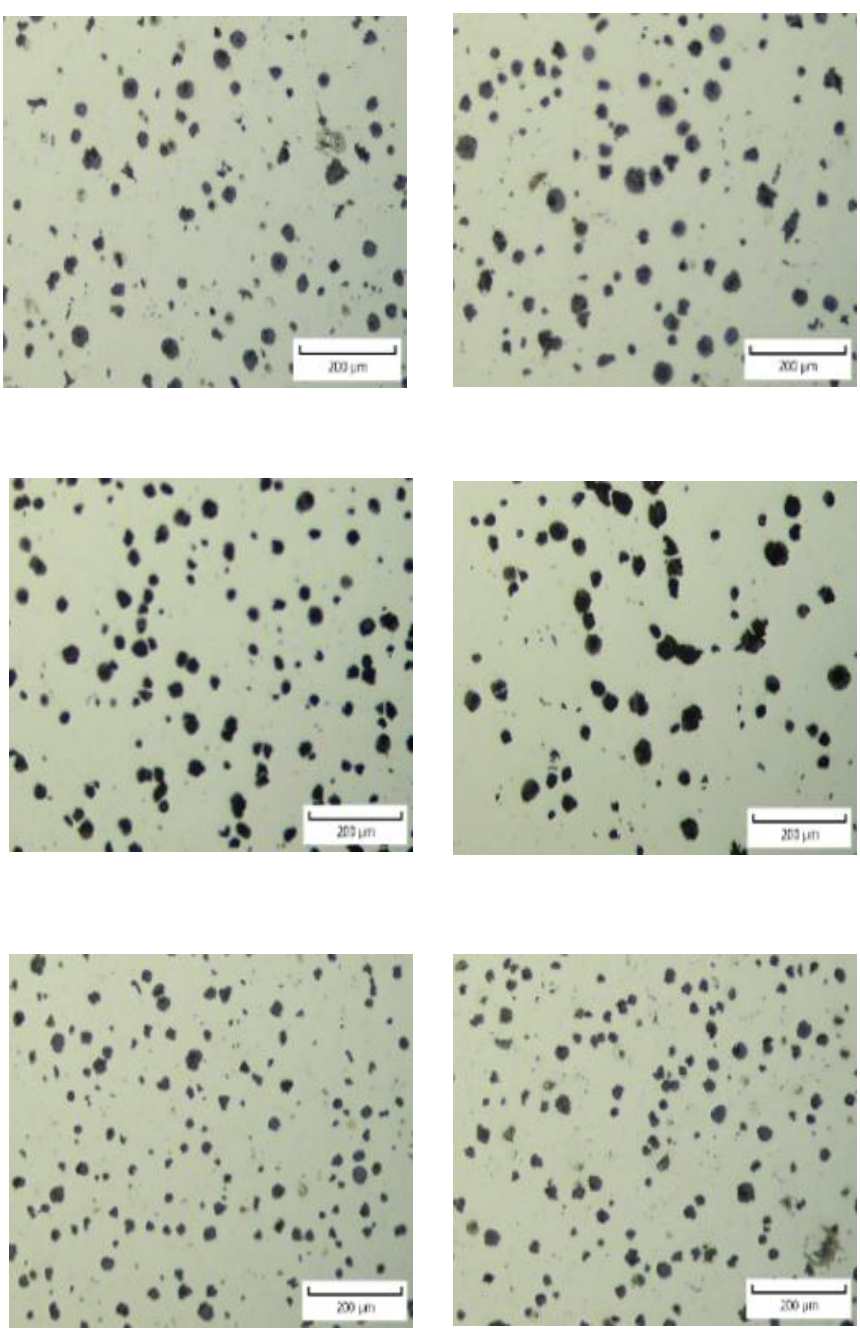

Figure 4 Graphite structure of the sample 515-517 


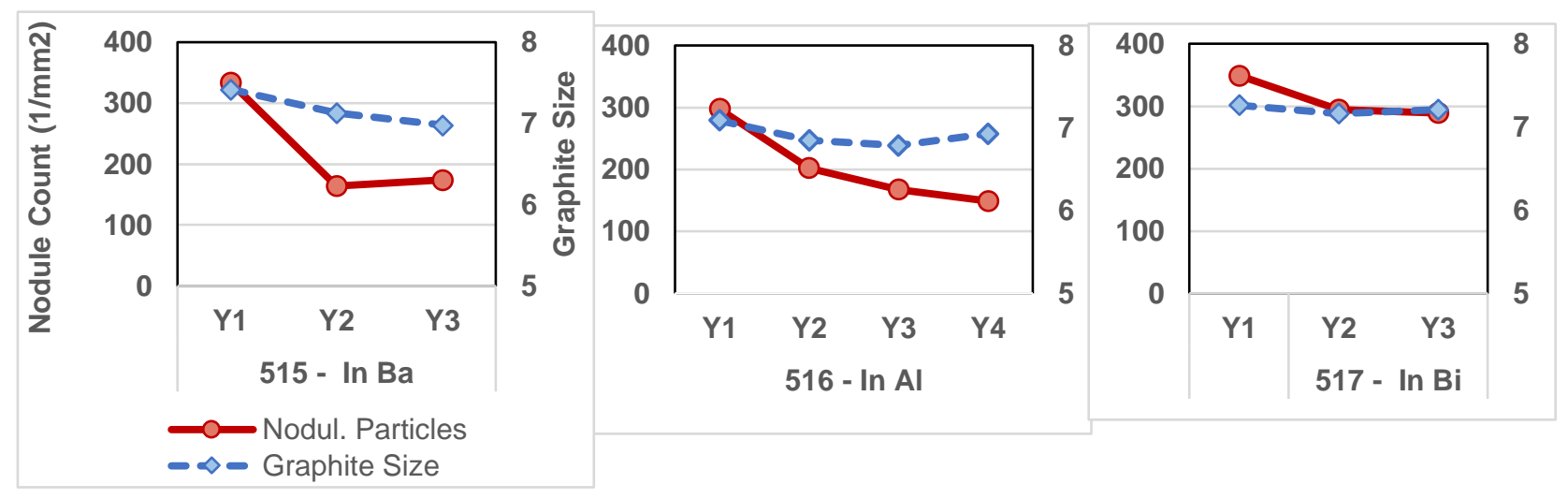

Figure 5 Dependence of the graphite size and nodule count on block thickness

Table 5 Graphite size and dispersion

\begin{tabular}{|c|c|c|c|c|c|c|c|c|}
\hline \multirow{2}{*}{ Inoculant } & \multicolumn{2}{|c|}{ Y1 } & \multicolumn{2}{c|}{ Y2 } & \multicolumn{2}{c|}{ Y3 } \\
\cline { 2 - 9 } & $\begin{array}{c}\text { Nodule Count } \\
\left(1 / \mathrm{mm}^{2}\right)\end{array}$ & $\begin{array}{c}\text { Graphite } \\
\text { Size }\end{array}$ & $\begin{array}{c}\text { Nodule Count } \\
\left(1 / \mathrm{mm}^{2}\right)\end{array}$ & $\begin{array}{c}\text { Graphite } \\
\text { Size }\end{array}$ & $\begin{array}{c}\text { Nodule Count } \\
\left(1 / \mathrm{mm}^{2}\right)\end{array}$ & $\begin{array}{c}\text { Graphite } \\
\text { Size }\end{array}$ & $\begin{array}{c}\text { Nodule Count } \\
\left(1 / \mathrm{mm}^{2}\right)\end{array}$ & $\begin{array}{c}\text { Graphite } \\
\text { Size }\end{array}$ \\
\hline In Ba & 334 & 7.4 & 164 & 7.1 & 174 & 7.0 & - & - \\
\hline In Al & 297 & 7.1 & 202 & 6.8 & 167 & 6.8 & 149 & 6.9 \\
\hline In Bi & 349 & 7.3 & 294 & 7.2 & 289 & 7.2 & - & - \\
\hline
\end{tabular}

\section{CONCLUSION}

Mechanical properties are not highly dependent on the thickness of the specimens. The strength and hardness values in the $\mathrm{Y} 1$ blocks are usually higher than in $\mathrm{Y} 2-\mathrm{Y} 4$ blocks, in which the influence of wall thickness appears to be less significant. No considerable difference of the inoculant type influence on mechanical properties by examined casting thickness was detected.

Impact energy as well as ductility increases with the increasing block thickness. The maximal values are obtained in the $\mathrm{Y} 4$ blocks presumably due to the higher ferrite content. The highest values of the impact energy were found after using the In-Al inoculant by all casting thicknesses, mainly in case of $\mathrm{Y} 1$ block. It seems, that inoculant of In-Al type is in the grafitisation point of view by thin wall castings most appropriate.

The graphite dispersion assesed as nodule count per $\mathrm{mm}^{2}$ decreases with the increasing thickness of the test blocks. The decrease is considerable especially in-between $\mathrm{Y} 1$ and $\mathrm{Y} 2$ blocks. In bodies with a greater thickness the change in the graphite dispersion is slower. When using the In-Ba and In-Al inoculants, the number of nodules lowers in the Y3 block almost to half the value of the Y1 block. When using the In-Bi inoculant, a significantly higher graphite dispersion was discovered as well as its less gradual decrease with an increasing wall thickness of the casting than with other inoculants.

The size of the graphite particles assessed by the "Graphite Size" criterion decreases with the increasing thickness of the bodies that means, that graphite get coarsen when casting thickness raises. The graphite size sensitivity on wall thickness in the case of In-Bi inoculant is significantly lower than by the another ones.

The basic metallic structure in all samples is ferrite-pearlitic. The ferrite composition was assessed according to the ČSN EN ISO 945-1 standard. The percentage of ferrite increases in all the cases of inoculation with raising of the block thickness. The ferrite increase is noticeable particularly after using the In-Al and In-Bi inoculants. 


\section{ACKNOWLEDGEMENTS}

This work was supported by the specific research project of BUT FME Brno, no FSI-S-19-5981 Research on rapid prototyping using investment casting technology.

\section{REFERENCES}

[1] HASSE, S. Ductiles Gusseisen. Berlin: Schiele\&Schön, 1996.

[2] The Sorel Metal Book of Ductile Iron. Canada: Rio Tinto Iron\&Titanium Inc, 2004

[3] SKALAND, T.A. Nucleation Mechanisms in Ductile Iron. In: Proceeding of the AFS Cast Iron Inoculation Conference. Schaumburg, Illinois, 2005, September.

[4] SKALAND, T.A. Inoculation Material Improves Graphite Formation in Ductile Iron. Modern Casting. 2001, vol. 91, no. 12 , pp. 43-45.

[5] BAI, J-X. Selection of Raw Materials and Control of Trace Elements for Production of High-Quality SC Iron. China Foundry. [online]. 2019, vol. 16, no.2, pp. 79-86. Available from: https://doi.org/10.1007/s41230-019-90006-9. 